\title{
ARTERIAL BLOOD GAS MEASUREMENTS IN THE MANAGE- MENT OF PATIENTS WITH CHRONIC BRONCHITIS AND EMPHYSEMA
}

\author{
BY \\ MARGARET M. PLATTS* AND MAVIS S. GREAVES \\ From the University Department of Medicine, Sheffield
}

(RECEIVED FOR PUBLICATION APRIL, 1957)

It is well known that a proportion of patients with severe emphysema develop anoxia and chronic respiratory acidosis (Taquini, Fasciolo, Suarez, and Chiodi, 1947, 1948; West, Baldwin, Cournand, and Richards, 1951; Cohn, Carroll, and Riley, 1954). We have made a particular study of the value of estimating the carbon dioxide tension and oxygen saturation of the arterial blood in the diagnosis, prognosis, and management of patients with chronic lung disease. This paper presents the results of observations made on such patients over a period of five years.

\section{MethodS}

Patients were considered to be suffering from heart failure when they had pitting peripheral oedema and the jugular venous pressure was elevated in all phases of respiration. All the patients were at rest when the specimens of blood were taken. The blood was obtained from the brachial artery and stored at room temperature in a stoppered syringe which had been rinsed with a solution of heparin.

The $p \mathrm{H}$ of the whole blood was measured within 10 minutes of withdrawal using a Marconi $p \mathrm{H}$ meter (type T.F. 511D) and a glass electrode. The blood was introduced anaerobically into a Stadie electrode vessel of 1.5 $\mathrm{ml}$. capacity surrounded by a water jacket at room temperature. The $p \mathrm{H}$ of the blood was compared with that of standard buffer solutions and a temperature correction of $-0.014 p \mathrm{H}$ unit per degree below $38^{\prime} \mathrm{C}$. was applied (Rosenthal, 1948). The carbon dioxide and oxygen saturation of the blood were measured by the manometric technique of Van Slyke and Neill (1924). The haematocrit was measured after centrifugation at 3,000 r.p.m. for 30 minutes. The carbon dioxide tension and bicarbonate content of the plasma were then obtained from the observed data using the nomogram of Singer and Hastings (1948).

\section{RESUlTS}

We have studied 77 patients with chronic pulmonary disease who had not developed heart failure

* J. G. Graves Research Fellow. In receipt of a grant from the Medical Research Council. or been treated with diuretics. Sixty-eight of them were suffering from chronic bronchitis and emphy- $\supset$ sema; the others were asth matic or had pulmonary $\vec{c}$ fibrosis or bronchiectasis. They have been observed $\mathbb{D}$ for periods varying from one to 60 months (average $\mathbb{D}$ 21.2 months). In many instances the arterial blood 3 has been analysed several times and the gas content $\stackrel{\mathbb{Q}}{-}$ varied considerably. For the purpose of com- $\overrightarrow{0}$ paring different patients in the diagrams those of results have been used which showed the highest carbon dioxide tension recorded in each individum. In 58 of these 77 patients the maximum recordet carbon dioxide tension was less than $55 \mathrm{~mm}$. He Many of the 19 patients who were found to have $\frac{\circ}{\varnothing}$ higher carbon dioxide tensions presented unusual $\stackrel{\varrho}{\rightarrow}$ clinical features. Seven of them subsequently developed heart failure (Fig. 1). One was suffering from one of the most severe bronchiolar infections encountered in the whole series and two other patients died three days after the investigation. One patient was comatose with depressed respiration after 3 grains $(180 \mathrm{mg}$.) of butobarbitone; her carbon dioxide tension had fallen to $46 \mathrm{~mm}$. $\mathrm{Hg} 3$. two weeks later. One patient with status asthmaticus also had normal blood gases one week later. The carbon dioxide tension in the arterial blood of $\mathrm{O}$ two other patients with severe bronchospasm was less than $50 \mathrm{~mm}$. Hg from one to two years later. The remaining five patients have maintained a high carbon dioxide tension in the arterial blood but have not, so far, developed heart failure. Only N five of the 58 patients in whom the carbon dioxide N tension was never found to be more than $55 \mathrm{~mm}$. 0 $\mathrm{Hg}$ have developed heart failure. These results show that a high tension of carbon dioxide in the $\frac{\sim}{\Phi}$ arterial blood of a patient with chronic pulmonary $\stackrel{9}{\rightarrow}$ disease may be a transient phenomenon associated with severe bronchospasm or pulmonary infection. If the condition persists, the patient is liable to $\mathbb{D}$ develop heart failure. 
FIG. 1.-Arterial blood gases of patients with chronic pulmonary disease who had not suffered from heart failure. O Patients with no history of heart failure. Patients who subsequently developed heart failure.

Eleven patients were observed before they developed heart failure and again during their first attack (Table I). With the onset of heart failure the oxygen saturation of the arterial blood invariably fell, but the changes in the carbon dioxide tension were less consistent; only three of the 11 patients showed a rise of more than $5 \mathrm{~mm}$. $\mathrm{Hg}$.

Most patients with pulmonary heart failure are more anoxic and hypercapnic than patients with similar pulmonary disease who have not suffered from congestive cardiac failure (Fig. 2). Eighty-five per cent. of the patients with no history of pulmonary heart failure had arterial blood which was more than $70 \%$ saturated with oxygen and in three.

TAELE I

ARTERIAL BLOOD GASES BEFORE AND DURING FIRST ATTACK OF PULMONARY HEART FAILURE

\begin{tabular}{|c|c|c|c|c|c|}
\hline \multirow{2}{*}{$\begin{array}{c}\begin{array}{c}\text { Patient } \\
\text { No. }\end{array} \\
1\end{array}$} & Date & \multicolumn{2}{|c|}{$\begin{array}{c}\mathrm{pCO}_{2} \\
(\mathrm{~mm} \cdot \mathrm{Hg})\end{array}$} & \multicolumn{2}{|c|}{$\begin{array}{l}\mathrm{O}_{2} \% \\
\text { Saturation }\end{array}$} \\
\hline & 2.3 .54 & $\begin{array}{l}\mathbf{A} \\
35\end{array}$ & B & $\begin{array}{l}A \\
82\end{array}$ & B \\
\hline & (Sept.'54) & & $17^{*}$ & & - \\
\hline 2 & $\begin{array}{l}29.3 .55 \\
(5.4 .55)\end{array}$ & 47 & & 89 & \\
\hline 3 & $\begin{array}{c}11.4 .55 \\
16.10 .51 \\
(17.1 .53)\end{array}$ & - & 47 & 82 & 88 \\
\hline 4 & $\begin{array}{l}26.1 .53 \\
13.11 .50 \\
(11.2 .52)\end{array}$ & - & 57 & 82 & 77 \\
\hline 5 & $\begin{array}{c}5.4 .52 \\
20.9 .54 \\
\text { (Feb.'55) }\end{array}$ & 49 & 62 & - & 62 \\
\hline 6 & $\begin{array}{l}16.2 .55 \\
31.3 .52 \\
(14.2 .55)\end{array}$ & 51 & 69 & 90 & 77 \\
\hline 7 & $\begin{array}{c}14.2 .55 \\
23.2 .55 \\
\text { (Jan.'56) }\end{array}$ & 56 & 65 & 79 & 63 \\
\hline 8 & $\begin{array}{c}27.1 .56 \\
1.2 .55 \\
(11.2 .55)\end{array}$ & 60 & 53 & 73 & 57 \\
\hline 9 & $\begin{array}{c}16.2 .55 \\
6.3 .56 \\
\text { (Jan.'57) }\end{array}$ & 61 & 65 & 86 & 41 \\
\hline 10 & $\begin{array}{c}18.1 .57 \\
6.6 .56 \\
\text { (Jan.'57) }\end{array}$ & 66 & 55 & 76 & 70 \\
\hline 11 & $\begin{array}{r}14.1 .57 \\
1.2 .55\end{array}$ & 57 & 66 & 78 & 70 \\
\hline & 9.2 .56 & & 64 & & 65 \\
\hline
\end{tabular}

$A=$ Before onset of congestive failure.

$\mathbf{B}=$ During first attack of congestive failure.

Dates in brackets are those on which oedema first developed.

* At the time this sample was taken, there was gross hyperventilation due to pulmonary artery thrombosis.

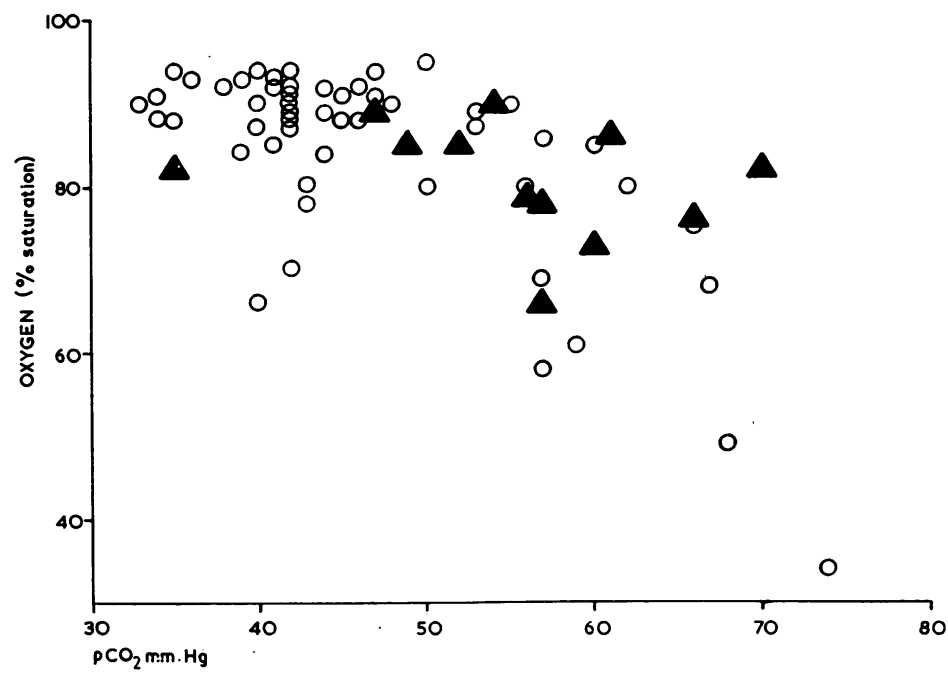

quarters the carbon dioxide tension was less than $55 \mathrm{~mm}$. Hg. On the other hand, two-thirds of the 36 patients with untreated pulmonary heart failure had arterial blood which was less than $70 \%$ saturated with oxygen and in $89 \%$ the carbon dioxide tension was $55 \mathrm{~mm}$. $\mathrm{Hg}$ or more.

The difference between the arterial blood gases in the two groups of patients is sufficiently consistent to provide a basis for differential diagnosis in heart failure. Respiratory acidosis is peculiar to patients with pulmonary heart fallure and is not found in other forms of cardiac failure (Campbell and Poulton, 1920; Fraser, 1927; Barach and Richards, 1931; Platts, 1953; Platts and Whitaker, 1954). Although the diagnosis of pulmonary heart failure is not usually difficult, cyanosed patients are occasionally encountered in whom it is difficult to determine, on clinical grounds, whether they are suffering from pulmonary heart failure or congenital heart disease. Two such patients were seen in this series.

The first patient was a man who presented with congestive cardiac failure, central cyanosis, and a loud parasternal systolic murmur. The right ventricle was enlarged and he had signs of bronchitis and emphysema. It was doubtful whether he was suffering from pulmonary heart failure or a right-to-left shunt of blood through a patent ventricular septum. However, the carbon dioxide tension in the arterial blood was $61 \mathrm{~mm}$. $\mathrm{Hg}$. The conclusion that he was suffering from cor pulmonale was subsequently confirmed by post-mortem examination.

The second patient was a woman aged 55 years with a long history of productive cough and breathlessness. She had congestive cardiac failure with central cyanosis and right-sided cardiac hypertrophy. As she was not hypertensive and had no cardiac murmurs, she was first 
FIG. 2.-Arterial blood gases of patients with chronic pulmonary disease. O Patients with no history of pulmonary heart failure. Patients with untreated pulmonary heart failure.

considered to be suffering from pulmonary heart failure. However, the carbon dioxide content of the blood was only $45.4 \mathrm{vol}$. $\%$, a value which is incompatible with a high carbon dioxide tension unless a gross metabolic acidosis coexists. At necropsy she was found to have a widely patent ductus arteriosus.

Clinical observation shows that certain patients with pulmonary heart failure will lose their venous congestion and oedema when treated with antibiotics and bronchodilator drugs alone, but more

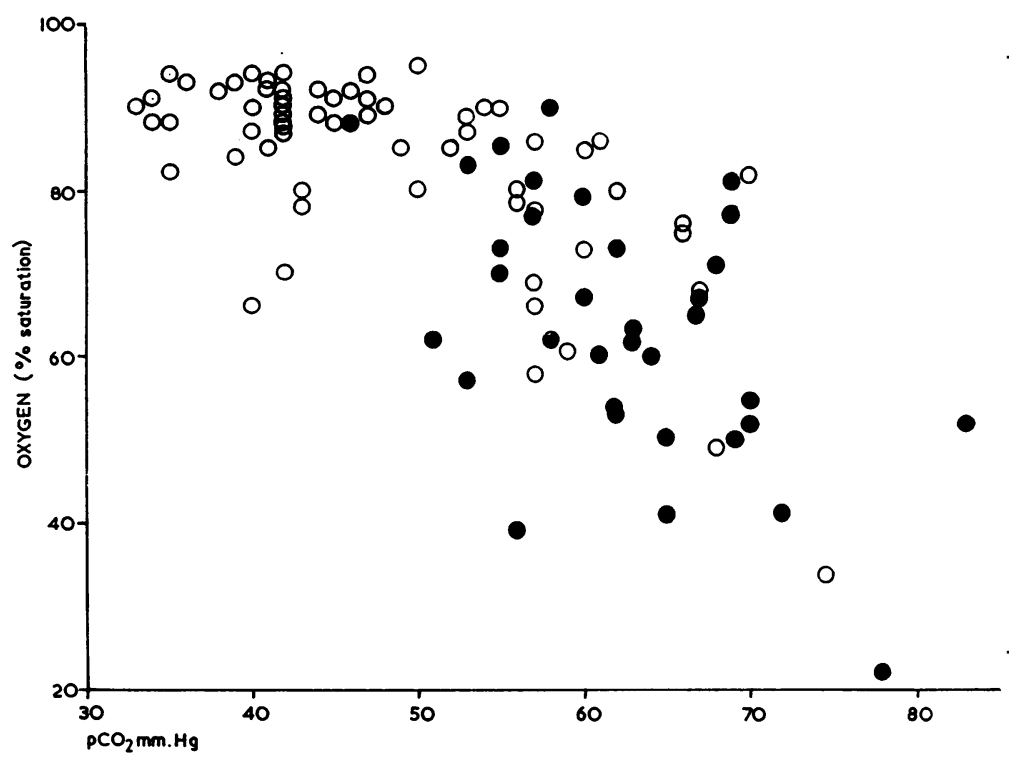
severely affected patients remain oedematous in spite of such treatment and may die unless they also receive mercurial diuretics. Again, some patients, after recovery from heart failure, may be kept free from oedema simply by moderate restriction of their salt intake. Others rapidly become oedematous again unless they receive diuretics regularly.

We have attempted to correlate the blood gas findings with the patients' need for diuretic treat-

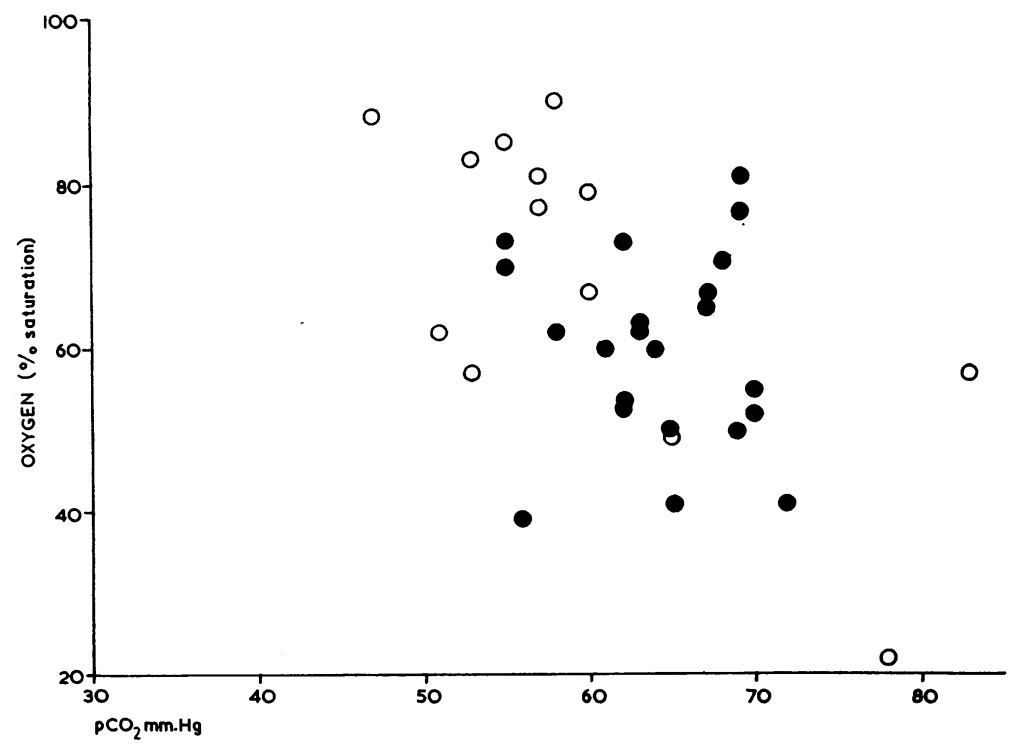

ment (Fig. 3). Thirty-six patients were examined $\mathcal{O}$ at the onset of their first attack of pulmonary heart. failure before any diuretics had been given. Thirteg of these patients did not require diuretics. Eigtit of them had arterial blood with a carbon dioxise tension under $60 \mathrm{~mm}$. $\mathrm{Hg}$ at the beginning of the

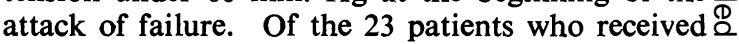
prolonged treatment with mercurial diuretics, only $\overrightarrow{\overrightarrow{0}}$ four had a carbon dioxide tension below $60 \mathrm{~mm}$. 3 Hg. Thus at the onset of an attack of pulmonary heart failure, those patients? who did not require diuretics had less disturbance of the을 arterial blood gases than those $\underset{\times}{\times}$ who subsequently needed intensive and prolonged treatment with these drugs.

The severity of anoxia and hypercapnia closely paralleled $\stackrel{5}{5}$ the mortality in our different $D$ groups of patients (Table II). The values for the oxygen saturation of blood given in Table II are those of the $\stackrel{0}{\circ}$ same specimens for which $\underset{\mathrm{C}}{\mathrm{N}}$ the figures for carbon dioxide

FIG. 3.-Arterial blood gases of patients with pulmonary heart failure. $O D$ Patients who recovered without $\bar{O}$ treatment with diuretics. Patients $\vec{D}$ who received prolonged treatment $?$ with diuretics. 
TABLE II

MORTALITY OF PATIENTS WITH CHRONIC PULMONARY DISEASE

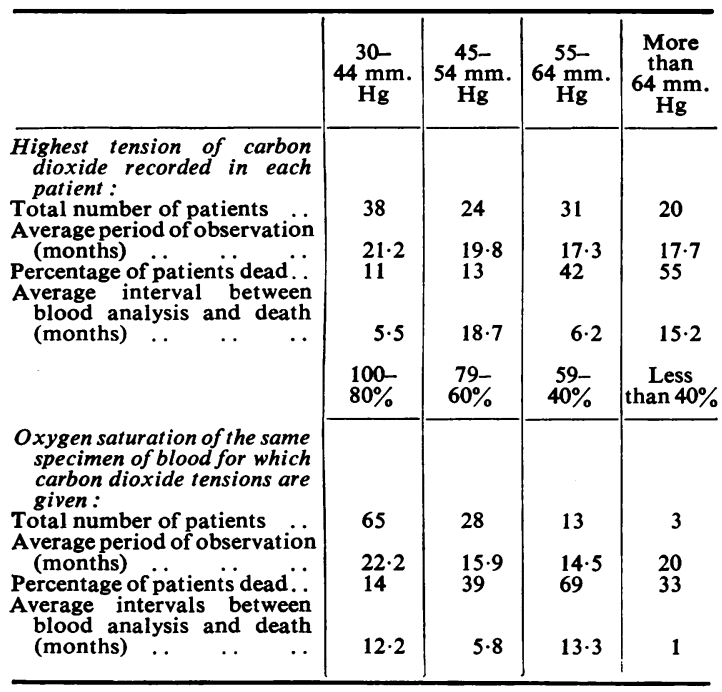

tension are quoted in the rest of this paper. They are therefore not necessarily the lowest oxygen saturation recorded in any particular patient and the blood was not always taken at the time when the patient appeared most cyanosed. A particularly high mortality was encountered in patients whose arterial blood was at any time found to be less than $50 \%$ saturated with oxygen. This occurred in 20 patients, all of whom had suffered from pulmonary heart failure. Eighteen of these died, eight within one month of the estimation. However, some survived for as long as two years though the oxygen saturation of the arterial blood exceeded $50 \%$ for most of this time. These were patients from whom a specimen of blood had been taken during an acute, severe pulmonary infection.

\section{Discussion}

West and others (1951) did not find a close correlation between the severity of emphysema as judged by the lung capacity, the volume of residual air, or the efficiency of intrapulmonary mixing of gas, and the development of pulmonary heart failure. Bates, Knott, and Christie (1956) found that the only measurement of pulmonary function which was considerably more abnormal in patients with emphysema who died within the ensuing six months than in the less severely affected patients was the carbon monoxide diffusing capacity in the lungs. No series of such measurements in emphysematous patients with pulmonary heart failure of varying severity has been published.
While observing many patients with chronic bronchitis and emphysema, we have learnt to recognize the serious import of a high or rising carbon dioxide tension in the arterial blood. We have found this a more useful sign of deterioration than other tests of pulmonary function. We have correctly predicted the onset of cardiac failure in several of our patients on the basis of a persistently high carbon dioxide tension in the arterial blood. Others are under close supervision because this complication appears imminent. In this way we hope to prevent the development of heart failure by treatment of pulmonary infection or to detcet and treat heart failure at an early stage.

There is sometimes doubt whether a patient will remain free from oedema once diuretic treatment has been stopped, and a number of patients may receive unnecessary injections of mersalyl because of this. We have ceased giving diuretics to some patients in whom the carbon dioxide tension of the arterial blood had fallen below $50 \mathrm{~mm}$. $\mathrm{Hg}$, and found that they remained free from oedema for many months. In those patients with very high carbon dioxide tensions, on the other hand, heart failure often recurred in spite of further treatment with diuretics.

An abnormally high carbon dioxide tension in the arterial blood indicates that pulmonary ventilation is impaired. It is not known why patients with this abnormality are liable to develop heart failure. However, experiments on animals and man have shown that anoxia or hypercapnia raises the pulmonary artery pressure (Binet and Bourlière, 1941 ; von Euler and Liljestrand, 1946; Motley, Cournand, Werko, Himmelstein, and Dresdale, 1947; Westcott, Fowler, Scott, Hauenstein, and McGuire, 1951). A linear relation has also been demonstrated between the carbon dioxide tension or the arterial oxygen desaturation and the pulmonary artery pressure in patients with pulmonary heart failure (Borden, Wilson, Ebert, and Wells, 1950; Harvey, Ferrer, Richards, and Cournand, 1951 ; Yu, Lovejoy, Joos, Nye, and McCann, 1953; Whitaker, 1954). Since it seems probable that pulmonary hypertension is an important cause of the right ventricular hypertrophy which characterizes pulmonary heart failure, the abnormalities in the arterial blood gases may be a direct precipitating factor in pulmonary heart failure. The retention of salt and water which must occur before peripheral oedema becomes apparent takes several days. If the patient should die or recover from the pulmonary infection in a shorter time, the signs of cardiac failure may not develop in spite of a temporary alteration of the arterial blood 
gases to levels characteristic of pulmonary heart failure.

The development of heart failure causes an increase in anoxia, presumably because pulmonary oedema hinders the diffusion of oxygen through the alveolar membrane. Since carbon dioxide is much more soluble than oxygen, its passage through the alveolar membrane is not greatly impeded by pulmonary oedema and therefore the carbon dioxide tension in the arterial blood is usually not greatly affected by the onset of pulmonary heart failure. The increased anoxia caused by pulmonary oedema is a potential cause of a further increase in pulmonary blood pressure and aggravation of heart failure. Thus a vicious circle may develop and it is well known that untreated patients with pulmonary heart failure usually deteriorate rapidly. Relief of anoxia and carbon dioxide retention, either by treatment of the pulmonary infection or by abolition of pulmonary oedema with diuretics, usually reverses this process.

Pulmonary heart failure occasionally develops in patients with no carbon dioxide retention. Patient 1 (Table I) was the only instance encountered in this series. He was suffering from pulmonary fibrosis due to sarcoidosis and had the physical signs of severe pulmonary hypertension. Similar patients have been described elsewhere (Austrian, McClement, Renzetti, Donald, Riley, and Cournand, 1951 ; Stone, Schwartz, and Green, 1956). Their pulmonary hypertension is believed to result from the obliteration of the pulmonary vasculature by fibrosis.

\section{SUMmaRY}

The carbon dioxide tension and oxygen saturation of the arterial blood from a series of patients with chronic pulmonary disease have been measured.

In $85 \%$ of the patients who had not suffered from pulmonary heart failure the arterial blood was more than $70 \%$ saturated with oxygen. The blood of $76 \%$ of these patients also had a carbon dioxide tension under $55 \mathrm{~mm}$. $\mathrm{Hg}$.

Two-thirds of patients with untreated pulmonary heart failure had an arterial oxygen saturation of less than $70 \%$ and the great majority of these $\mathrm{e}^{\vec{*}}$ patients had an arterial carbon dioxide tension of more than $54 \mathrm{~mm}$. $\mathrm{Hg}$.

Fifty per cent. of patients who had a carbono dioxide tension persistently over $54 \mathrm{~mm}$. $\mathrm{Hg}$ ando had not suffered from pulmonary heart failure developed this condition during the following year.

Patients whose arterial blood was more than $80 \%$ saturated with oxygen or had a carbon dioxide tension of less than $55 \mathrm{~mm}$. $\mathrm{Hg}$ at the onset of an attack of pulmonary heart failure usually recovered ${ }^{x}$ without treatment with mercurial diuretics.

Forty-four per cent. of patients whose arteriai blood was less than $50 \%$ saturated with oxygenw died within one month.

We are greatly indebted to Professor C. H. StuartHarris for constant helpful advice and criticism. Dr. T.es Hanley has given us invaluable assistance in the pre $\frac{\mathbb{D}}{\mathrm{D}}$ paration of the manuscript.

\section{REFERENCES}

Austrian, R., McClement, J. H., Renzetti, A. D., Donald, K. W. 은 Riley, R. L., and Cournand, A. (1951). Amer. J. Med., 11, 667. $\rightarrow$ Barach, A. L., and Richards, D. W. (1931). Arch. intern. Med., $48, \frac{\mathrm{G}}{325 .}$

Bates, D. V., Knott, J. M. S., and Christie, R. V. (1956). Quart. J. V Med., 25, 137.

Binet, L., and Bourlière, F. (1941). C.R. Soc. Biol. (Paris), 135, 990

Borden, C. W., Wilson, R. H., Ebert, R. V., and Wells, H.S. (1950)

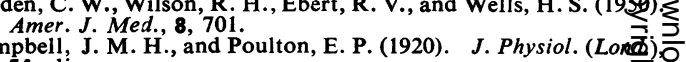

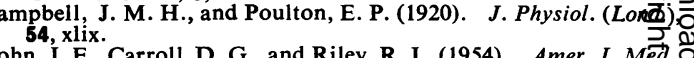

Cohn, J. E., Carroll, D. G., and Riley, R. L. (1954). Amer. J. Med. A uler, U. S. von, and Liljestrand, G. (1946). Acta physiol. scand. 12, 301

Fraser, F. R. (1927). Lancet, 1, 589.

Harvey, R. M., Ferrer, M. I., Richards, D. W., and Cournand, A 3 (1951). Amer. J. Med., 10, 719. Motley, H. L., Cournand, A., Werko, L., Himmelstein, A., and
Dresdale, D. (1947). Amer. J. Physiol., 150, 315 .

Platts, M. M.(1953). Clin. Sci., 12, 63.

and Whitaker, W. (1954). Amer. Heart J., 48, 77.

Rosenthal, T. B. (1948). J. biol. Chem., 173, 25

Singer, R. B., and Hastings, A. B. (1948). Med cine (Baltimore) 27, 223.

Stone, D. J., Schwartz, M. J., and Green, R. A. (1956). Amer. J Med., $2 i, 211$.

Taquir,i, A. C., Fasciolo, J. C., Suarez, J. R. E., and Chiodi, $\mathrm{H}$ (1947). Amer. Heart J., 34, 50.

-_ (1948). Arch.intern. Med., 82, 534.

Van Slyke, D. D., and Neill, J. M. (1924). J.biol. Chem., 61, 523.

West, J. R., Baldwin, E. de F., Cournand, A., and Richards, D. W? (1951). Amer. J. Med., 10, 481.

Westcott, R. N., Fowler, N. O., Scott, R. C., Hauenstein, V. D., and음 McGuire, J. (1951). J. clin. Invest., 30, 957.

Whitaker, W. (1954). Quart. J. Med., n.s.., 23, 57.

Yu, P. N. G., Lovejoy, F. W., Joos, H. A., Nye, R. E., and McCann W. S. (1953). J. clin. Invest., 32, 130. 